\title{
Perancangan Jaringan Skala Besar dengan Menggunakan Metode Border Gateway Protocol (BGP) Berbasis Mikrotik
}

\author{
${ }^{1}$ Ronald David Marcus, ${ }^{2}$ Eleazar Tfuakani \\ ${ }^{1}$ Dosen Prodi Sistem Informasi, Universitas Merdeka Malang, Indonesia \\ ${ }^{2}$ Mahasiswa Program Studi Sistem Informasi, Universtas Merdeka Malang, \\ Indonesia
}

E-mail: 1'redastrea800@gmail.com, ${ }^{2}$ eleazartfuakani@gmail.com

\begin{tabular}{l}
\hline Tersedia Online di \\
\hline http://www.jurnal.unublitar.ac.id/ \\
index.php/briliant \\
\hline
\end{tabular}

\section{Sejarah Artikel}

Diterima pada 28 Agustus 2019

Disetujui pada 31 Agustus 2019

Dipublikasikan pada 31 Agustus

2019 Hal. 401-409

\section{Kata Kunci: \\ BGP (Border Gateway Protocol), Routing Protocol, Desain BGP}

\section{DOI:}

http://dx.doi.org/10.28926/briliant .v3i4.361

\begin{abstract}
Abstrak: Tujuan dari penelitian ini adalah untuk merancang Routing Protocol menggunakan virtual microphones dan winbox sebagai alat untuk membuat BGP serta membuat konektivitas dan komunikasi antar jaringan. Desainnya adalah untuk mempelajari kinerja jaringan komputer, studi kasus di Universitas Merdeka Malang untuk meningkatkan layanan internet melalui manajemen jaringan internal. Metode yang digunakan oleh metode protokol routing antara sistem otonom. BGP memiliki pertukaran data atau informasi dengan jaringan yang diperoleh oleh sistem BGP itu sendiri dan dapat memperoleh informasi yang sudah terdaftar dalam sistem otonom (AS). Hasil studi pabrikan virtual ini memberikan gambaran umum untuk membuat jaringan protokol perutean BGP dan meminimalkan biaya yang sangat mahal karena BGP dapat mengurutkan tujuan pengguna di dalam negeri dan luar negeri dengan jalur berbeda di jaringan yang sama.
\end{abstract}

\section{PENDAHULUAN}

Penerimaan teknologi merupakan kunci utama dalam melangkah ke penerapan atau penggunaan teknologi informasi. Dengan menerima teknologi dan merasakan manfaat dan kemudahan dari penggunaan teknologi salah satunya penggunaan jaringan skala besar dengan metode BGP menjadikan pengguna merasakan kepuasan dan sukses terhadap penggunaan teknologi tersebut. Penelitian terdahulu meneliti penerimaan teknologi informasi dengan mengukur kesuksesan penggunaan sistem informasi dan penerimaan teknologi (Andarwati \& Jatmika,2017; Andarwati, Nirwanto, \& JT, 2018; Nirwanto, 2019)

Protocol router berfungsi untuk menghubungan serta mengintegrsikan antar jaringan secara handal sehingga dapat mengakomodasi kebutuhan pengguna. Protocol router terbukti sangat dibutuhkan untuk bertukar informasi data-data, diantara pada perguruan tinggi, instansi, dan kantor pemerintahan. Selain itu Selain dibutuhkan router yang handal dibutuhkan juga konfigurasi dan penggunaan protokol (aturan - aturan) tertentu agar komunikasi antar jaringan dapat terhubung dengan baik. Salah satu protokol yang sering digunakan adalah BGP (Border Gateway Protocol). Desain BGP yang dibuat untuk membantu dalam mengembangkan routing protocol tersebut (Hidayanto, 2012). 
Border Gateway Protocol mampu mengontrol dan mengatur trafik-trafik dalam network multi-home dengan sumber yang berbeda dan ttersambung lebih dari 1 Internet Service Provider. Tujuan Border Gateway Protocol adalah memperkenalkan kepada publik di luar network (upsteram provider atau peer) tentang rute atau porsi spasi address yang dimiliki dengan ijin membawa data ke address tujuan meng-advertise. Salah satu kelemahan yang dihadapi oleh BGP routing adalah mempublikasikan rute yang tidak diketahui bagaimana cara mencapainya. Hal semacam ini dinamakan black-holing artinya melakukan advertise atau meminta izin untuk membawa data, namun beberapa bagian dari spasi address merupakan milik orang lain, akibatnya proses advertise malah menyulitkan (Octaviani Annisa, 2015).

Permasalahan pada penelitian ini adalah (1) bagaimana mendesain routing protocol menggunakan virtual mikrotik dan winbox sebagai sarana pembuatan jaringan BGP?. (2) Bagaimana sambungan internet terkoneksi secara fisik tersebut terjadi hubungan atau komunikasi antara jaringan satu dengan yang lain ditentukan oleh baik atau tidaknya sambungan pada tiap-tiap jaringan?.

Tujuan penelitian adalah (1) mendesain routing protocol menggunakan virtual mikrotik dan winbox sebagai sarana pembuatan jaringan BGP. (2) Menciptakan konektivitas hubungan dan komunikasi jaringan satu dengan yang lain agar menjadi lebih baik dan bermanfaat dengan menggunakan border gateway protocol yang merupakan metode protocol routing interautonomous system. Sehingga lebih mempermudah dalam mendapatkan informasi berupa data.

Border Gateway Protocol (BGP) merupakan sebuah protocol routing yang digunakan untuk mentransfer data informasi antara gateway dengan host yang berbeda dan lalu lintas rute di internet atau Autonomous System (AS). Alur sistem penentuan topologi jaringan serta jaringan VPN MPLS dan perangkat lunak penunjang. Serta semua router di jaringan VPN MPLS dengan scenario pengujian dan analisa hasil. Autonomous System (AS) adalah sekelompok network yang berada dibawah satu kontrol administrasi yang bisa saja seperti ISP atau organisasi perusahaan besar. AS memiliki sekolompok router yang terbentuk dalam jaringan dan juga berada dalam hak administrasi, kepemilikan, kepentingan, dan mengunakan konfigurasi policy yang sama. Biasanya satu AS bebas berkomunikasi dan membagikan data dengan router-router yang terhubung dalam satu protocol jaringan (Musril, 2012).

\section{METODE}

BGP (Border Gateway Protocol) merupakan sebuah metode protocol routing inter-autonomous system. BGP sendiri memiliki fungsi bertukar data atau informasi dengan jaringan yang dijangkau oleh sistem BGP itu sendiri, dan dapat mendapatkan informasi yang memang sudah list dalam autonomous system (AS). BGP mengunakan sebuah jalur protocol transport, yaitu TCP (Transmission Control Protocol) (Rendy Hidayanto, 2012). Ada 2 BGP yaitu IBGP (Internal BGP). Sesuai dengan namanya, internal BGP atau IBGP adalah sebuah sesi BGP yang berada di satu administrator atau AS. Biasanya IBGP digunakan untuk saling tukar rute-rute yang di dapat dari dunia luar. Sehingga jika sudah banyak RUTE yang di dapat maka makin banyak pilihan untuk menuju ke suatu situs. Dan EBGP (External BGP), Sebaliknya dengan iBGP, jika iBGP itu harus berada di 
Autonomous System atau adminstrator yang sama lain halnya dengan EBGP. EBGP dapat terhubung walau dengan Autonomous Syatem atau administrator yang berbeda. EBGP biasanya dibuat menggunakan jaringan Point-To-Point mau itu wireles Point-To-Point dan yang lainnya (Musril, 2012).

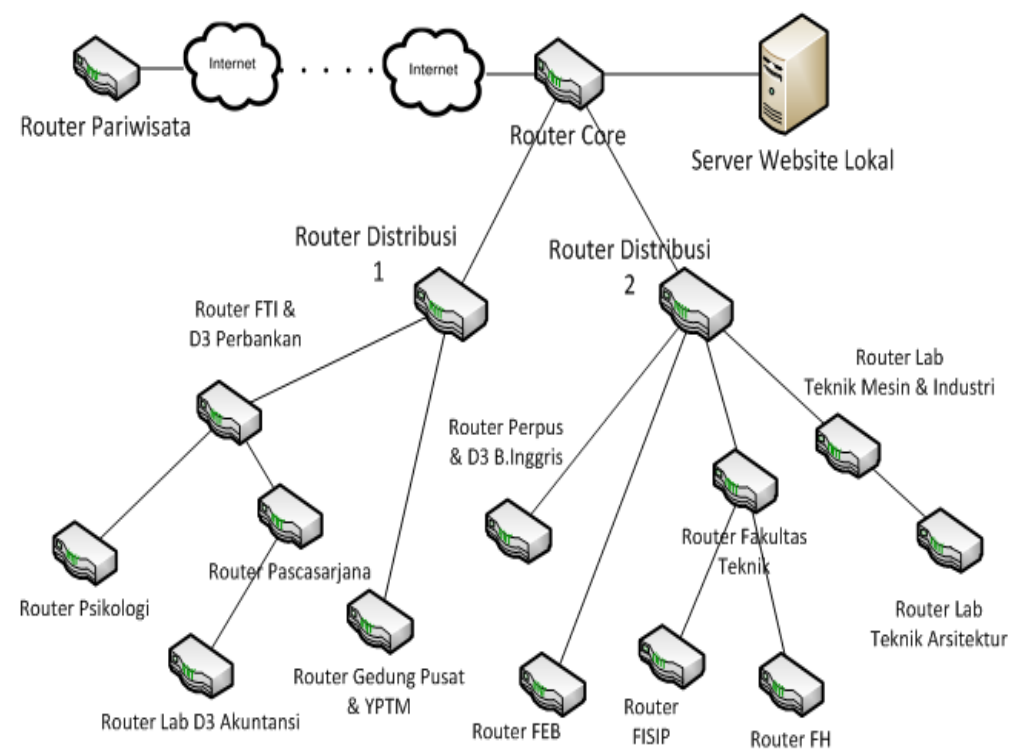

Gambar

1.Jaringan Universitas Merdeka Malang

Gambar 1 menyajikan cara kerja Routing Protocol BGP baru dapat katakan bekerja pada sebuah rouer jika sudah saling terbentuk komunikasi dengan router tetangganya yg juga menjalankan BGP. Sesi komunikasi ini adalah berupa komunikasi yg menggunakan port TCP dengan nomer 179. Setelah sudah saling terkomunikasikan, barulah kedua buah router BGP tersebut bisa saling bertukar informasi (Octaviani Annisa, 2015).

\section{HASIL}

\section{Rancangan Topologi}

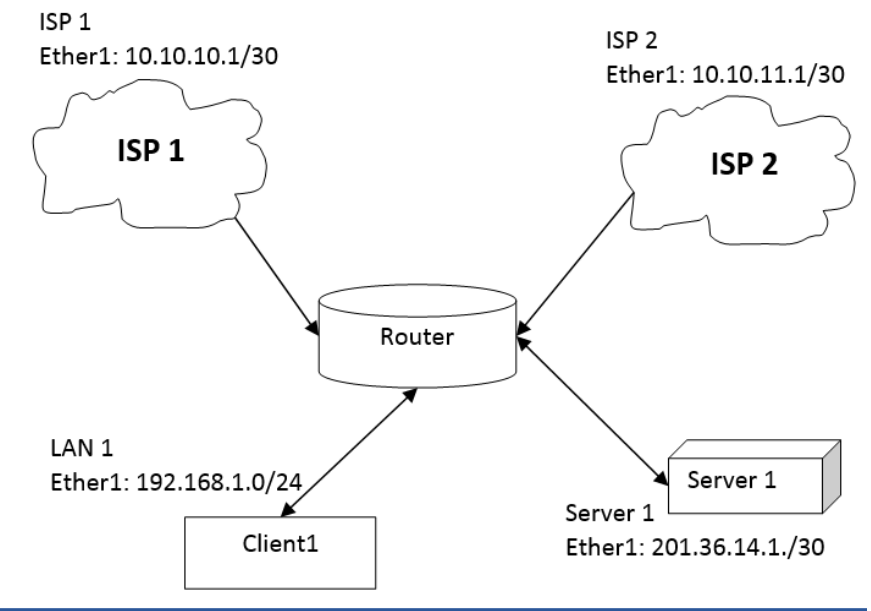

Gambar 2. Desain Topologi BGP 
Gambar 2 menunjukkan bahwa dalam rancangan topologi jaringan BGP ini penulis mengilustarikan 2 ISP yang berbeda yaitu ISP1 dan ISP2 yang dihungkan ke router. Pada topologi tersebut mengunakan 2 ISP, 1 Router, 1 Lan dan 1 server dan serta dengan IP masing-masing. Inilah topologi sederhana yang dapat digunakan dan dikembangkan sesuai dengan kapasitasnya karna jaringan BGP ini sendiri bisa lebih lagi seperti menghubungkan 2 ISP dalam 1 konfigurasi jaringan yang sama.

\section{Pembuatan Virtual Mikrotik Dan Konfigurasi BGP}

Pembuatan Virtual Box, ini akan coba dibahas tentang bagaimana alur dari konfigurasi jaringan BGP yang sederhana mengunakan virtual box, mikrotik dan winbox. Pembuatan mikrotik virtual, hanya perlu menentukan Lokasi Penyimpanan mikrotik, Ram, dan Kapasitas yang digunakan oleh Mikrotik tersebut. Setelah ikut akan masuk ke tampilan awal mikrotik (Syah, 2019). Setelah itu tinggal menentukan jalur masuk untuk windoxnya, seperti konfigurasi ini.

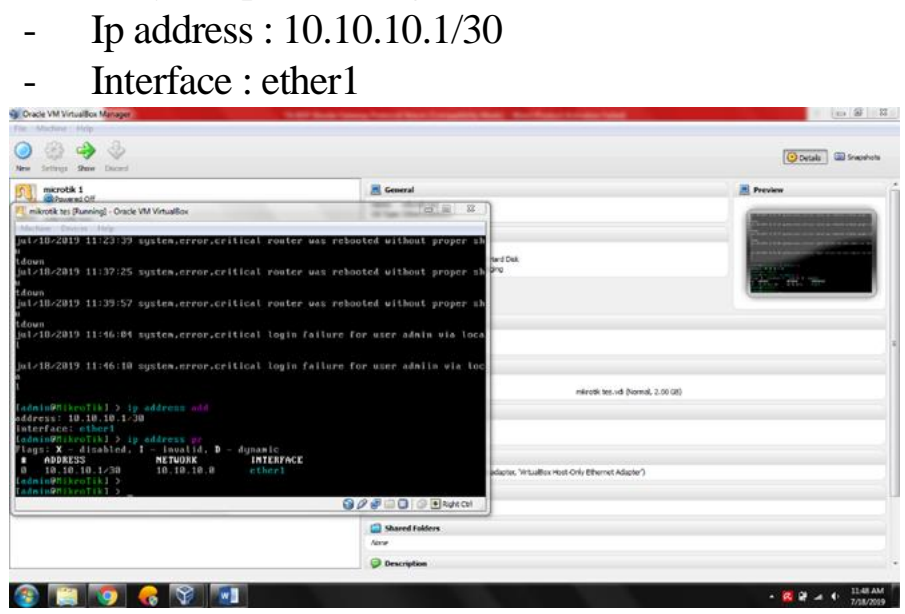

Gambar 3. Tampilan Mikrotik Virtual

Gambar 3 menunjukkan bahwa penggunaan Windox untuk mengkontrol virtual mikrotik yang sudah dibuat. Kelanjutan dengan pilih IP yang sudah terdaftar disajikan pada gambar 4 dibawah ini.

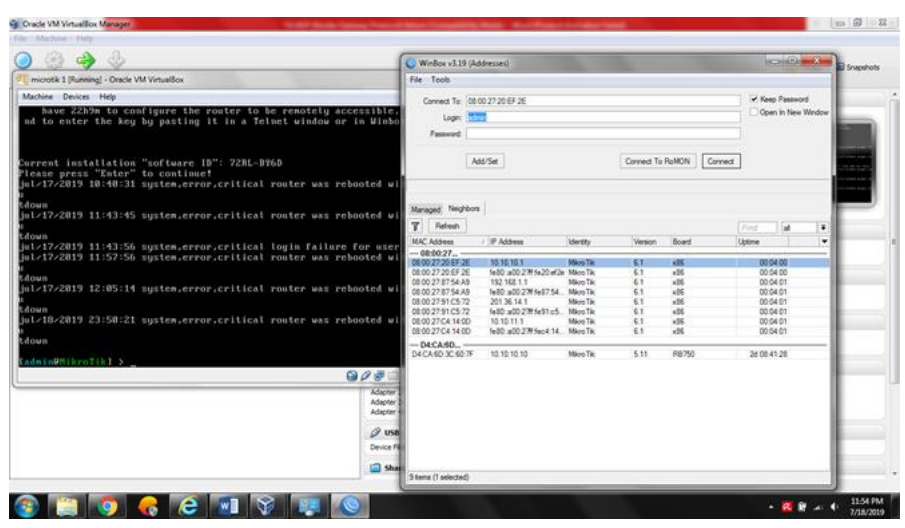

Gambar 4. Tampilan Windox 
Gambar 4 menunjukkan bahwa ketampilan awal akan menetukan IP ISP, LAN dan SERVER. masuk ke winbox langsung saja setting ip addres dengan caranya klik $\rightarrow$ IP $\rightarrow$ Pilih Adress lalu klik tanda + lalu isikan ip address, interfacenya. Selanjutnya gambar 5 menyajikan tentang tampilan BGB berikut dibawah ini.

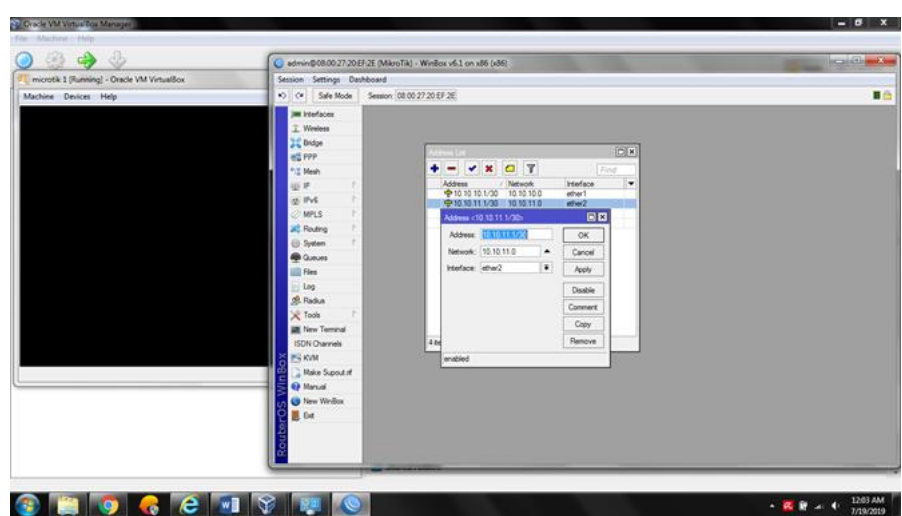

Gambar 5. Tampilan BGP

Setelah itu gambar 5 menyajikan tentang proses masuk pada konfigurasi BGP yang simple, dengan cara klik routing $\rightarrow$ BGP dan tinggal di isikan.

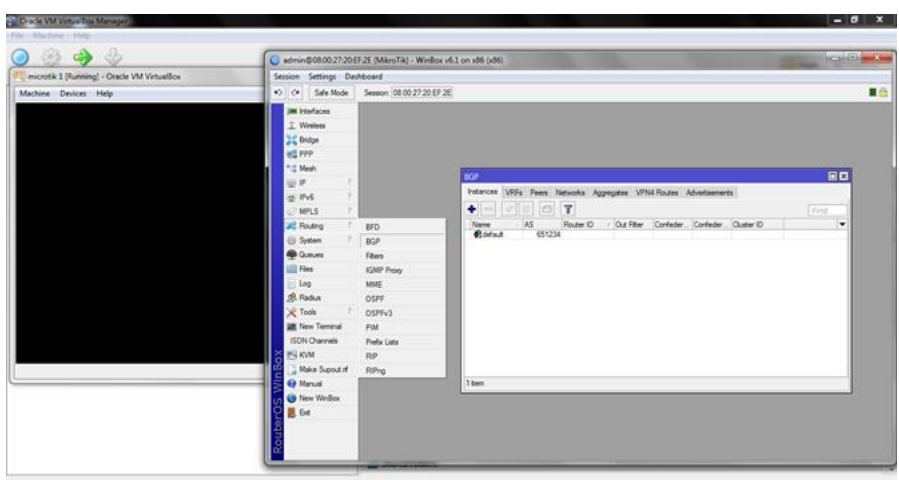

(9)

Gambar 6. Tampilan BGP

Gambar 6 menunjukkan tentang tab menu instance klik tanda + lalu tentukan nilai dari parameter ASN (Autonomous System Number). Bisa tambahkan satu profile intsance baru atau juga bisa mengubah konfigurasi pada profile yang telah ada (default). Nilai dari ASN ini sesuaikan dengan informasi dari ISP.

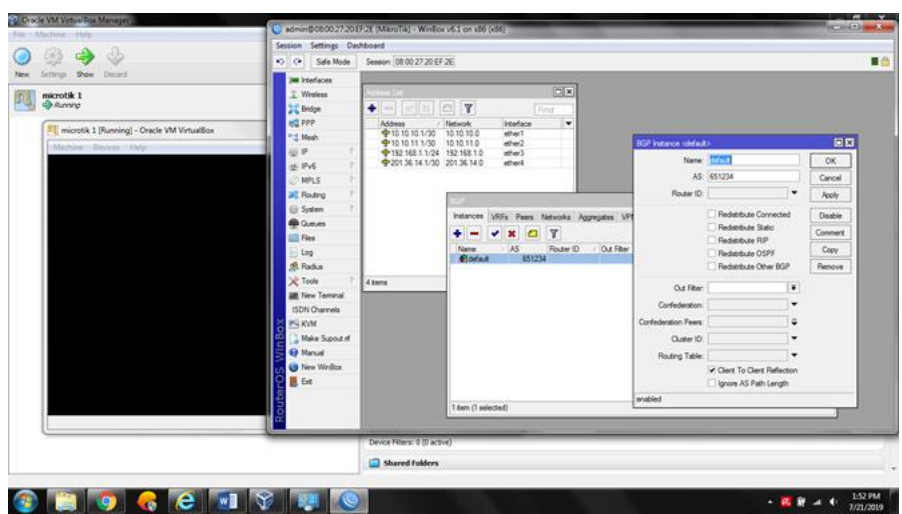

Gambar 7. Tampilan BGP Preers 
Gambar 7 menyajikan tentang cara mengatur ASN BGP, akan membuat jalur ke router lain caranya pilih Routing $\rightarrow$ BGP $\rightarrow$ Peers, lalu juga akan melakukan konfigurasi pada tab 'Peers'. Disini akan menambahkan dua buah rule untuk peering (memasangkan) dengan BGP Router yang ada di ISP. Tambahkan peering untuk link koneksi isp1 dan isp2.

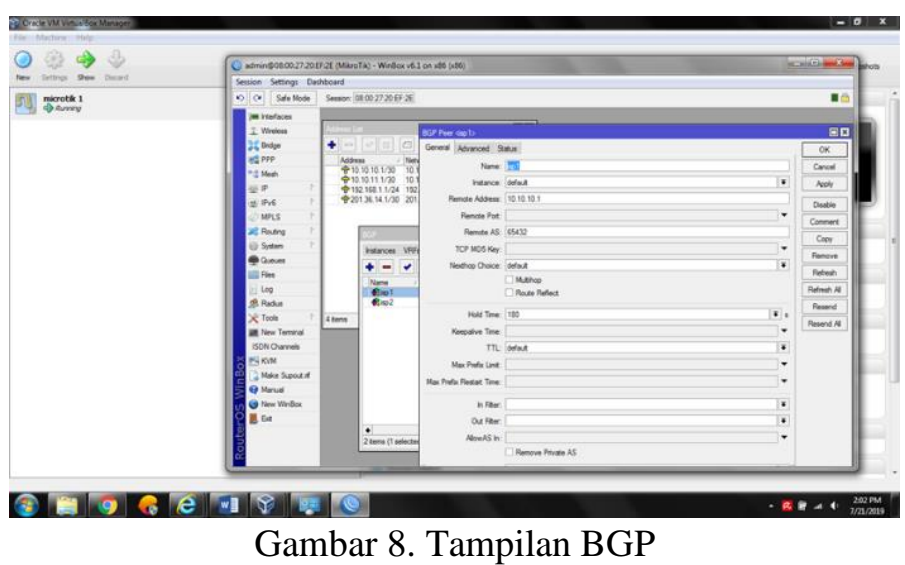

Gambar 8 menyajikan tentang tampilan BGP setelah mencoba lihat setting yang telah lakukan tersebut dengan cara klik IP $\rightarrow$ pilih routes maka akan muncul tampilan berikut:, akan muncul konfigurasi biasa karna menggunakan virtual mikrotik. Apabila proses 'peering' berhasil maka pada kolom state akan mucul keterangan 'Established' dan jika melihat melalui New terminal dengan script :routing bgp peer pr, maka pada dua rule yang buat tadi terdapat flag 'E'.

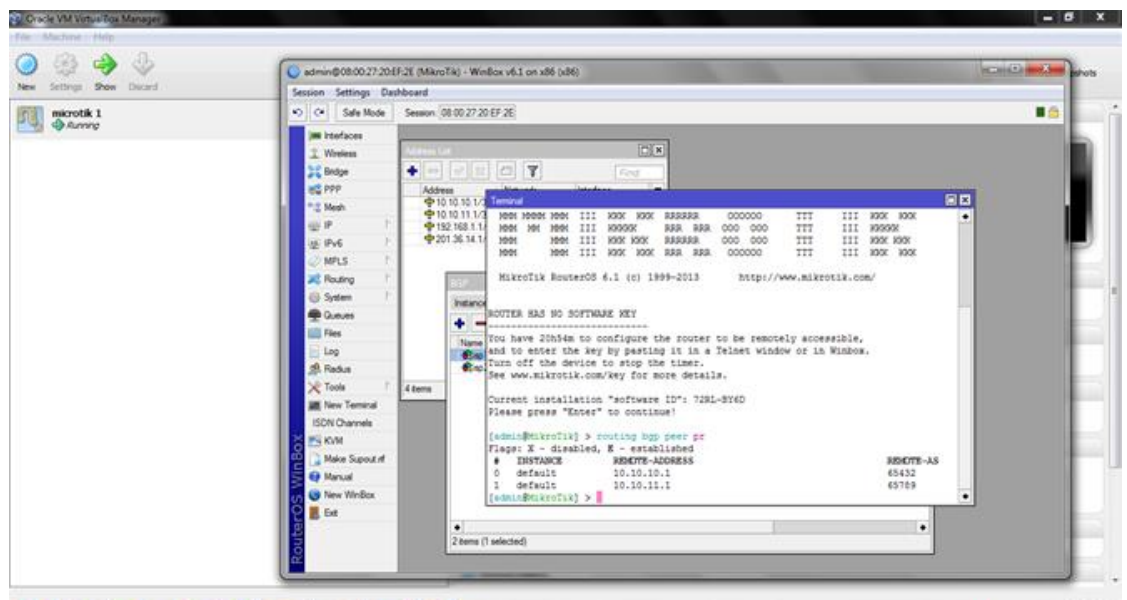

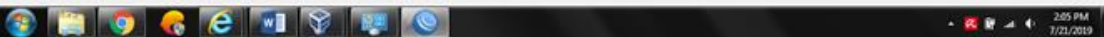

\section{Gambar 9. Terminal Mikrotik}

Gambar 9 menyajikan terminal mikrotik dengan hasil akhir konfigurasi ini menunjukan konfigurasi BGP. Dari langkah ini seharusnya LAN dan SERVER sudah bisa koneksi ke internet. Nah, demikianlah langkah-langkah bagaimana cara konfigurasi dasar dari BGP. Anda bisa sesuaikan lokasi ip addressing sesuai dengan kondisi real pada jaringan Anda. 


\section{PEMBAHASAN}

Pembahasan kali ini membahas akan membahas mengapa BGP digunakan dan worth it atau tidak serta, melihat bahwa konfigurasi yang di buat sangat simple melihat dari kondisi jaringan yang ada di universitas merdeka malang. Dari tampilan jaringan bisa saja memberikan alur dari luar untuk memperbaiki koneksi jaringan yang ada di unmer setiap router yang di digungkan bisa tersambung dengan IBGP untuk membuat alur yang lain dalam jaringan tersebut.

Konfigurasi diatas mengunakan 2 ISP, 1 ROUTER, 1 LAn dan 1 SERVER EBGP dengan IP yang ditentukan dan AS. Dan setiap router dapat mengenali router yang tersambung dengan IP yang sudah dimasukan. Diketahui bahwa BGP diciptakan untuk menggantikan protokol routing EGP yang mengizinkan routing secara tersebar sehingga tidak harus mengacu pada satu jaringan backbone saja.

\section{ISP 1}

Ip Address :10.10.10.1/30

10.10.11.1/30

Network: 10.10 .10 .0

Interface: ether1

ASN: 65432

\section{$\underline{\text { LAN }}$}

Ip Address : 192.168.1.1/24

Network: 192.168.1.0

Interface: ether3
ISP 2

Ip Address:

Network: 10.10.11.0

Interface: ether2

ASN: 65789

\section{SERVER}

Ip Address: 201.36.14.1/30

Network: 201.36.14.0

Interface: ether4

BGP merupakan routing protocol yang mudah dikontrol bebas oleh pengguna karena banyak sekali kebutuhan menjadi terpenuhi oleh adanya BGP karena sangat tepat sekali jika penggunaannya diterapkan di perusahaan, instansi, perguruan tinggi, lembaga pemerintahan untuk koneksi jaringan internet wilayah yang luas. Serta memiliki 2 jalur keluar menuju internet ini disebuat dengan multihoming. Jaringan ini umumnya adalah jaringan berskala sedang hingga skala besar seperti ISP, Bank, perusahaan BUMN, Lembaga pemerintahan, institusi swasta, perguruan tinggi. Dan jaringan tersebut memiliki Blok IP dan ASN sendiri. Peran BGP dalam jaringan multihoming ini sangat besar yaitu:

1. Sebagai routing protocol dengan menggunakan pertukaran routing dengan ISP atau NAP yang posisi berada di atas jaringan.

2. Adanya perpaduan BGP melalui pengaturan dan kebijakan yang fleksibel serta dapat membuat sistem load balancing traffic dengan sistem keluar masuk.

3. BGP merupakan routing protocol yang sangat reliable serta fleksibel dalam bekerja dikarenakan BGP selalu menggunakan protokol TCP untuk berkomunikasi dengan jaringan-jaringan yang lainnya meskipun terpisah dalam melakukan pertukaran informasi. TCP merupakan protokol yang menganut system reliable service, dimana setiap rute komunikasi yang dibangun berdasarkan protokol ini harus dipastikan sampai tidaknya. Pemastian ini dilakukan menggunakan sistem Acknowledge terhadap setiap retu komunikasi yang terjadi. Dengan demikian, hampir tidak ada informasi routing dari BGP yang tidak 
sampai ke perangkat tujuannya. Routing protocol BGP yang sekarang banyak, digunakan adalah BGP versi 4 atau lebih sering disingkat sebagai BGP-4.

\section{KESIMPULAN}

Dari hasil di atas tugas akhir ini ada beberapa kesimpulan yang diambil BGP tidak hanya berhenti sampai sini karena ini hanyalah dasar-dasarnya saja. Karna masih banyak trik yang dapat di implementasikan, BGP adalah sebuah protokol routing yang mudah dan simple bila digunakan. Jaringan BGP menggunakan router virtual mikrotik ini telah selesai di konfigurasi dan berhasil dibuat dengan menyambungkan jaringan yang besar. Dalam pembahasan BGP memberikan pengetahuan bagi penulis dan yang membaca.

\section{SARAN}

Berikut adalah saran yang diberikan untuk dapat mengembangkan tugas akhir ini menjadi lebih baik :

1. Diharapkan jaringan BGP dapat di kemabangkan lagi sesuai sesuai kebutuhan yang diperluakan oleh pengguna.

2. Sebelum melakukan konfigurasi BGP dan implementasi jaringan, diharapkan agar untuk melakukan pemeriksaan terhadap inrastruktur jaringan yang digunakan, mulai dari pengkabelan, interface ethernet, konektivitas antar perangkat jaringan. Pastikan beberapa hal diatas sudah berhasil dan bekerja sesuai dengan perancangan yang dibuat.

3. Saran terakhir adalah diharapkan penelitian selanjutnya dapat mengembangakan atau menerapkan sistem monitoring trafik pada tiap tiap router jaringan yang dilewati dan prinsip path vector routing protokol.

\section{DAFTAR RUJUKAN}

Andarwati, M., \& Jatmika, D. (2017). Analisis Pengaruh Kualits Sistem Informasi Akuntansi Terhadap Penerimaan Teknologi di Sektor UKM dengan Pendekatan Model TAM. Seminar Nasional Sistem Informasi (Senasif 1), pp. 946-956). Fakultas Teknologi Informasi UNMER Malang.

Andarwati, M., Nirwanto, N., \& JT, D. (2018). Analysis of Factor Affecting The

Succesof Accounting Information Systems Based on Information Technology on SME Managementsas Accounting InformationEnd User. EJEFAS Journal, 97-102.

Hidayanto, R. (2012). Implementasi Load Balancing Menggunakan Metode Bgp (Border Gateway Protocol) Di Mikrotik Pada Studi Kasus Jaringan Pascasarjana UPN "Veteran" Jatim. Surabaya: Skripsi, Universitas Pembangunan Nasional "Veteran".

Musril, H. A. (2012). Simulasi Interkoneksi Antara Autonomous System (AS) Menggunakan Border Gateway Protocol (BGP). Jurnal Nasional Informatika dan Teknologi Jaringan (InfoTekJar), 2(1), 1-9.

Nirwanto, N. d. (2019). MardianaEnd-user Satisfaction as asn Impact of The System Quality, Information Quality, and Top Management Support The Perceived Usefulness of Technology Utilization. Journal of Marketing 
Development and Competitive. Journal of Marketing Development and Competitiveness, 13(1), 59-75.

Octaviani Annisa, V. (2015). Pengukuran Dan Analisa Waktu Konergensi Protokol Routing Eksternal Border Gateway Protocol (BGP) Menggunakan GNS3. Yogjakarta: Skripsi. Universitas Sanata Dharma Yogyakarta.

Syah, S. (2019). Buku Panduan Mikrotik. (https://www.academia.edu/ 9586820 /BUKU_PANDUAN_mikrotik), diakses 20 mei 2019). 